\title{
PRINCÍPIOS DE AVALIAÇAO PÓS-OCUPAÇÃO (APO) E DESEMPENHO TÉCNICO APLICADOS À EDIFICAÇÃO DA FACULDADE DE CIÊNCIAS APLICADAS (FCA) DA UNICAMP (LIMEIRA-SP)
}

\section{Erica de Matos Miranda*, Gerusa de Cassia Salado.}

\section{Resumo}

Neste trabalho aplicou-se a metodologia de Avaliação Pós-Ocupação (APO) em uma área selecionada da Faculdade de Ciencias Aplicadas (FCA) da UNICAMP, localizada no campus de Limeira-SP. Foi feita uma avaliação as-built sobre o edificio, inspeções in loco e uma analise com base na NBR 15575, buscando avaliar o real estado da edificação que possui 9 anos de uso.

\section{Palavras-chave:}

Avaliação Pós-Ocupação, Faculdade de Ciencias Aplicadas (FCA), NBR 15575.

\section{Introdução}

A Avaliação Pós-Ocupação (APO) é uma técnica aplicada desde a Segunda Guerra Mundial em países da Europa e nos Estados Unidos, surgida para calcular os efeitos pós-guerra em meados de 1945; hoje também é utilizada para aperfeiçoar a construção, possibilitando um edifício que satisfaça as expectativas dos usuários e traga benefícios de conforto e bem estar (ORNSTEIN, 2017).

Nesta pesquisa foi realizado um estudo sobre os princípios da Avaliação Pós-Ocupação (APO) referentes ao quesito técnico-construtivo aplicado no edifício da Faculdade de Ciências Aplicadas da UNICAMP (FCA). O objetivo foi selecionar pontos do edifício que aplicassem a metodologia de APO e referentes ao critério de desempenho da NBR 15575.

\section{Resultados e Discussão}

A FCA foi inaugurada no ano de 2009 e faz parte do Campus II da UNICAMP na cidade de Limeira, interior de São Paulo. Possui um terreno de $485 \mathrm{mil} \mathrm{m}^{2} \mathrm{com}$ aérea construída de $30 \mathrm{mil} \mathrm{m}^{2}$. Com seis cursos oferecidos no campus em período integral e noturno, a faculdade possui um grande numero de discentes, docentes e funcionários utilizando o edifício ao longo de sua historia.

Mesmo com pouco tempo de uso a FCA apresenta diversas patologias em seus edifícios. A APO contribui para uma melhor administração de benfeitorias, permitindo que o ciclo da construção não seja linear e o edifício seja condenado depois de seu tempo de uso, mas, tornando o edifício adaptável ao contexto para qual fim é destinada de acordo com a avaliação dos usuários fazendo seu ciclo uma espiral (Figura 1).

Segundo levantamento bibliográfico e analise da norma NBR 15575, os edifícios necessitam de critérios para poder mensurar seu desempenho. O objetivo dessa pesquisa é avaliar o melhor critério para analisar a situação da FCA e escolher o edifício da faculdade que mais se adeque a analise por APO.

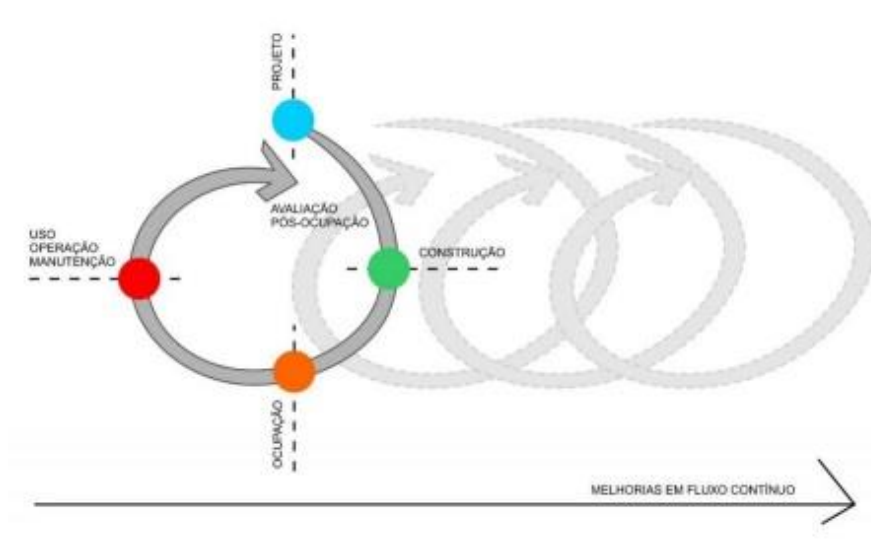

Figura 1. Visão Contemporânea do Processo de Projeto, Ocupação, Uso Operação e Manutenção para a melhoria continua do Ambiente Construído.

A pesquisa foi realizada de abril/2018 a julho/2018 e continuará sendo realizada até atingir o resultado esperado.

\section{Conclusões}

A partir das pesquisas realizadas, pode-se concluir que um edifício submetido à APO garante uma maior vida útil a construção, pois além de indicar patologias avalia a satisfação do usuário com a obra em prol de melhoria continuas.

\section{Agradecimentos}

Agradeço ao CNPq pelo financiamento oferecido, aos meus familiares por sempre me incentivarem e a minha orientadora Prof ${ }^{-}$Dr ${ }^{\text {a }}$ Gerusa Cássia Salado por todo o suporte durante toda a pesquisa.

ABNT NBR 15575-1/2013, Edificações Habitacionais Desempenho - Parte 1: Requisitos gerais;

ORNSTEIN, Sheila Walbe. AVALIAÇÃO PÓS-OCUPAÇÃO (APO) NO BRASIL, 30 ANOS: O QUE HÁ DE NOVO? Revista Projetar - Projeto e Percepção do Ambiente, São Paulo, v. 2, n. 2, p.7-22, ago. 2017. 